\title{
PARA UNA CARACTERIZACIÓN TIPOLÓGICO-RETÓRICA DEL TEXTO VERBAL PUBLICITARIO
}

\author{
Rocío Lineros QuiNTERo \\ (Universidad de Murcia)
}

\begin{abstract}
RESUMEN
This study aims at a detailed analysis of the structures and functions of texts; with this purpose, a particular discursive-textual type has been used, namely, Publicity and, with it, the publicity text, that is, the advertisement. Therefore, the author's work has been to show, and at the same time to advocate for, the need of a SCIENCE OF THE TEXT.

The function of this new Science concerns the description and explanation of the internal and external relations of the different aspects of the forms of communication and the uses of a language; and in this process, it acquires a specific condition: it becomes a cross-sectional science, cutting across several disciplines. This has led us to an interdisciplinary approach in our analysis of the publicity verbal text, taking into account its relation to Rhetoric, to Grammar and to Linguistics.
\end{abstract}

Podemos afirmar, junto con Teun A. Van Dijk, que «nuestros textos persuasivos siguen empleando operaciones retóricas que los oradores ya empleaban hace dos mil años en las asambleas públicas o ante los tribunales»' ${ }^{1}$.

Esta es una de las razones primordiales que nos llevan a sostener la importancia de la intercesión que ahora tratamos, esto es, RETÓRICA VERSUS PUBLICIDAD; entendiendo este «versus» no como contraposición sino como el camino que nos lleva «hacia». Un camino que se desarrolla ya en los oradores greco-latinos de forma asombrosamente persuasiva, como ahora lo hacen nuestros más destacados publicistas: los oradores del siglo xx. A este respecto entendemos la retórica moderna como aquel subdominio del estudio del discurso que trata específicamente las estrategias de persuasión. Las estructuras retóricas de un

T. A. Van Dijk, La ciencia del texıo, Barcelona, Paidós, 1983, pp: 26. 
discurso pueden aparecer en cualquier nivel. No debemos hablar, por consiguiente, de un nivel de descripción sino de una dimensión específica de descripción, que atraviesa todos los niveles del discurso.

La unidad denominada texto ${ }^{2}$ es característica del nivel lingüístico correspondiente; a saber, el nivel textual, cuya formulación es consecuencia de la existencia de propiedades lingüísticas específicas; tales propiedades tienen que ver con la dimensión comunicativa de lo textual. En este sentido el texto puede ser definido como la menor unidad dotada de autonomía comunicativa. De esta definición se deduce que lo que llamamos texto es una unidad de carácter semántico que, junto al comunicativo, son en el texto sus propiedades más significativas.

Por consiguiente, la individualización de un texto depende, en efecto, de su autonomía semántico-comunicativa y de su sentido preciso, distinto e independiente de otros niveles gramaticales. Esta diferente naturaleza del texto precisa su inclusión en la jerarquía de niveles en un lugar distinto que refleje sus peculiaridades diferenciales con respecto al resto de niveles, esto es;

(1) JERARQUÍA DE NIVELES LINGÜÍSTICOS

v) nivel oracional

iv) nivel sintagmático

iii) nivel de la palabra

ii) nivel monemático

i) nivel fono-fonológico

En consecuencia, nuestra presentación de una dimensión específica de descripción, la retórica, que atraviesa todos los niveles del discurso queda explícita, directamente, en el nivel textual; así, podemos sostener que la retórica ejerce su estudio sobre el nivehtextual y desde él, a los otros niveles lingüísticos.

Debemos pensar inicialmente en la gramática y en su ámbito de estudio así como en sus reglas, estructuración y convencionalidad, para llegar a determinar la clase de expresiones que son convencionalmente aceptables en la comunidad lingüística. Esta aceptabilidad, a saber, gramaticalidad ${ }^{3}$, tiene que ver claramente con los elementos estructurales de la retórica; esto es, la Inventio, Dispositio y Elucotio, que pasamos a presentar aunque sólo sea sucintamente.

2 En la formulación de Teun A. Van Dijk, «... término que denota la construcción teórico abstacta que subyace a lo que normalmente se llama discurso». Cfr. T. A. Van Dijk, Texto y contexto, Madrid, Cátedra, 1988, pp: 32.

3 También dekemons tener en cuenta la importancia que las fronteras de la gramaticalidad poseen ya que su ade ........u. en varios niveles de descripción y de comprensión hará que cada tipo específico de discurso obtenga características propias. 
La reconstrucción teórico-gramatical de las expresiones en el nivel significativo viene a ser completada por el concepto retórico de «inventio», entendido éste como el hallazgo de ideas en la mente del creador. Estas ideas son ordenadas por la «dispositio» y trasladadas al lenguaje por medio de la «elocutio», siendo esta última verdadera formulación linguiística y emparentada directamente con la gramática.

La función básica de la dispositio consiste en la distribución de un todo (por tanto, del conjunto del discurso así como también de sus partes integrantes: res y verba). Aunque la dispositio, como segunda fase del proceso elaborativo, hay que colocarla detrás de la inventio en esa relación temporal dentro del proceso de elaboración, no se trata de una sucesión estrictamente separada y distinguible. Más bien, inventio y dispositio se hallan vinculadas una a otra de manera inseparable.

Esta segunda fase del proceso elaborativo es la que impide el caso de las ideas y de las palabras al someter res y verba al orden, puesto éste al servicio de la utilitas ${ }^{4}$. La dispositio constituye el complemento necesario de la inventio, que sin ella sería un proceso inconexo. Pero, además de esto, la dispositio no sólo se halla subordinada a la res (en la inventio), sino también lo está a los verba y, por ende, a la elocutio.

Pero esquematicemos más detalladamente, aunque sea de modo introductorio, nuestro objeto de estudio, que vendrá reflejado del siguiente modo:

(2)

A

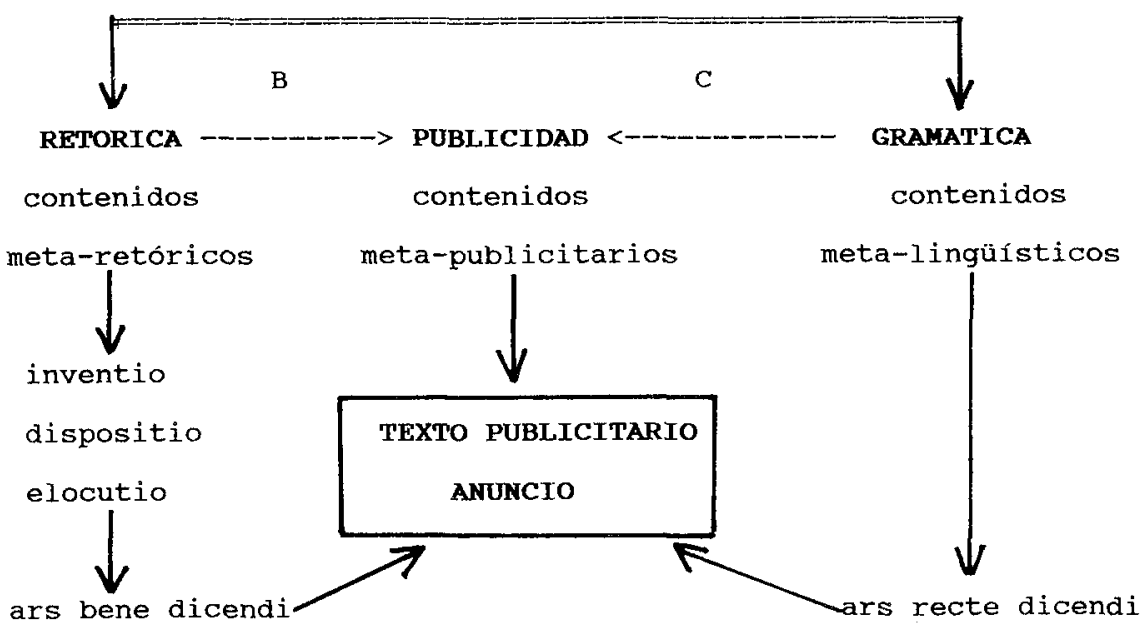

4 Cfr. H. Lausberg, Manual de retórica literaria, Madrid, Gredos, 1984, T.I, pp: 372. 
La relación de interdependencia (A) o las de determinación (B-C) son las que nos lievan a sostener el carácter interdisciplinario que la publicidad posee y que es persuasivamente presentado por el texto propagandístico; por consiguiente, entendemos el anuncio como la base primordial en la cual se desarrollan dichas relaciones. Es en el manifiesto publicitario ${ }^{5}$ donde se establecen formalmente los contenidos significativos que la publicidad posee y que han sido tomados tanto de la retórica como de la gramática.

Es necesario que explicitemos el contenido del término «manifiesto publicitario». Tomamos este concepto de la concepción que Roland Barthes posee $^{6}$; distinguiendo en el interior de cada anuncio varios tipos de mensajes, a saber:

«i.- un primer mensaje cuyo vehiculo es el componente escrito, que lendrá, por tanto, naturaleza lingüística;

ii.- un mensaje icónico codificado y

iii.- un mensaje icónico no codificado, consistente en la reproducción analógica de objetos reales, con lo que los signos están en relación no arbitraria: el denominado mensaje perceptivo o imagen denotada».

En consecuencia, entendemos el anuncio como soporte de esta sustancia informativa compleja; por ello, todo anuncio podrá estar formado por una pluralidad de mensajes distintos y de diferente función dentro de la totalidad del manifiesto.

Inicialmente el mensaje publicitario, y con él la publicidad en sí, adopta la inventio y la dispositio para la expresión perfecta de aquello que se quiere comunicar; esto es, de aquello a que se quiere persuadir. Son estos elementos retóricos los que mueven a la acción que posteriormente será llevada a cabo por el receptor, ahora consumidor.

En la inventio se expresan los objetivos publicitarios, la res inicial que conlleva el comportamiento de aquél a quién va dirigido el mensaje. Estos objetivos se hallan a su vez sometidos a estructuras mentales que vienen determinadas por los factores de la invención, pudiendo ser entendidos también como «técnicas de persuasión»?

Dentro de estas técnicas es importante destacar el cómo de tales procedimientos persuasivos. Una vez decidida la técnica que va a utilizarse, es de gran valor presentar el modo en que tal actitud, positiva o negativa, va a ser enfocada. Es aquí donc s entran en juego las distintas motivaciones en la inventio del mensaje que serán completadas con las connotaciones que el ámbito metalingüístico nos ofrece.

$s$ Cfr. E. Feliú García, Los lenguajes de la publicidad, Alicante, Secretariado de publicaciones de la Universidad de Alicante, 1984, cap: III.

- R. Barthes, Elementos de semiología, Madrid, A. Corazón, 1970.

7 Cfr. D. Victoroff, La publicidad y la imagen, Barcelona, Gustavo Gili, 1980. 
En páginas anteriores señalamos la importancia del binomio res-verba; si en la inventio se expone la res y en la elocutio los verba, conectados éstos directamente con la gramática, es en la dispositio donde los elementos res-verba toman cuerpo como tal binomio.

Las ideas halladas en la inventio son estructuradas e, incluso, jerarquizadas en la dispositio, donde el manifiesto publicitario toma valor propio en todas sus manifestaciones. La disposición del objeto persuasivo es presentada en la estructura global del anuncio publicitario; esto es, en el encabezamiento (headline), cuerpo del tex to y rúbrica, que vienen expresados en las tácticas de enunciado y de enunciación.

Muy en consonancia está la estructura global con la iconicidad, si sostenemos que el anuncio publicitario no se termina en el mensaje sino en el cuerpo global del texto, esto es, en el «icono» ${ }^{8}$. A este respecto nos hallamos no sólo con los elementos metalingüísticos sino con aquellos que son exclusivamente metapublicitarios y que están dirigidos primordialmente hacia el objetivo inicial: la persuasión. La colocación del texto en el marco global del anuncio, la

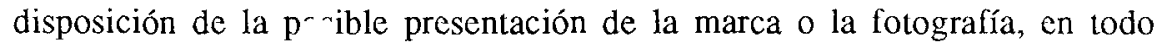
momento persuasiva y en consonancia con el texto, forma del cotex to ${ }^{9} \mathrm{del}$ anuncio dentro de su contexto global ${ }^{10}$.

Finalmente, la elocutio constituye la manifestación formal de las significaciones, debiendo notarse que no es solamente la exteriorización por medio del lenguaje lo que en la elocutio presentamos, sino que son también importantes a este respecto los otros sistemas que la publicidad utiliza. Así, no encontramos con la manifestación clara de otros,códigos que, junto con el mensaje, forman el todo del anuncio. Por lo tanto, en la componente escrita de los manifiestos publicitarios aparecen, junto a ese código escritural, otros cuyos función principal puede ser la de enfatizar, por lo que sobrepasan los límites del código linguiístico, funcionando respecto a éste como «códigos complementarios» ${ }^{11}$ que pueden superponerse. Por consiguiente, «en nuestro caso tendríamos un código o medio cuyo campo específico es el de la significación, y otros cuyo campo sería el de la sobresignificación, que actúan en el área escritural como los sustitutos de los elementos paralingüísticos» ${ }^{12}$.

8 Entendemos por icono la imagen global del anuncio de la cual forman parte tanto la componente escrita como la componente fotográfica y objetual. Para mayor precisión véase $\mathrm{D}$. A. Aader y Myers, Management de la publicidad, Barcelona, Hispanoeuropea, 1991 y J. Saborit,La imagen publicitaria en televisión, Madrid, Cátedra, 1988.

$9 \quad$ Cfr. T. A. Van Dijk, La ciencic del texto, Barcelona, Paidós, 1983.

10 Todos estos elementos no lingüísticos son denominados por Teun $\mathrm{A}$. Van Dijk «marcas agramaticales» admiento que dichas marcas «... no operan dentro de la gramática sino más bien sobre ella». T. Van Dijk, «La pragmática de la comunicación literaria» en AA.VV., Pragmática de la comunicación literaria, Madrid, Arcolibro, 1986, pp: 171-195.

1 Cfr. Jeanne Martinet, Claves para la semiología, Madrid, Gredos, 1970, pp: 175.

12 Cfr. E. Feliú García, op. cit., pp: 136. 


\section{I.- LA INVENTIO DEL MENSAJE PUBLICITARIO}

Analizar el fin que la publicidad y su mensaje persiguen, esto es, la persuasión y con ella el cambio de actitud, no es tarea fácil si tenemos en cuenta la importancia que en este ámbito poseen las estructuras, íntimamente ligadas a los objetivos publicitarios. Tales estructuras vendrán modeladas por las técnicas persuasivas, siendo en la dispositio publicitaria donde se pongan de manifiesto las ideas halladas en la inventio.

La actitud, el cambio, la actividad y la acción en el proceso persuasivo son los ejes «isotópicos» ${ }^{13}$ del manifiesto publicitario. Junto a estos conceptos que nos ilevan al análisis profundo del mundo publicitario, otros como propósito o intención crean los valores primordiales del «plan persuasivo». Plan estructurado en estadios cognoscitivos que llevan consigo los ejes isotópicos anteriormente mencionados, esto es, la atención y la interpretación. Ambos estadios deben ser sometidos a la mente y, en concreto, a la memoria y al conocimiento del receptor, el cual se halla abocado, ante tal situación cognoscitiva, al cambio de actitud, propósito inicial en el campo publicitario y persuasivo.

Globalmente, este círculo cerrado que la publicidad lleva consigo, comenzando con el propósito y finalizando con el cambio de actitud, trata los tres pilares de mayor envergadura en toda comunicación: la emisión, el mensaje y la recepción.

Quizás no hallemos una definición más exacta de los objetivos publicitarios que la misma publicidad nos puede ofrecer. Este es el caso ante el cual nos encontramos al anunciarse una empresa publicitaria:

(t.1) «La buena publicidad ayuda a vender.

La buena publicidad es, además, rentable».

La venta es, primordialmente, la base de todo objetivo publicitario, pero a ella no se llega sin haber existido antes un proceso de persuasión influyente en el comportamiento final del receptor. Sometido a esta influencia persuasiva se encuentra el habitual consumidor, centro ahora del plan de marketing publicitario, que será estudiado en sus más diversos caracteres - la edad, el estado civil, la profesión, el sexo, el lugar de residencia, el estilo de vida, los ingresos, la cultura-; por consiguiente, el consumidor llegará a ser el principal punto de mira para las estrategias persuasivas que el anunciante desea llevar a cabo.

Una de las funciones primordiales que todo objetivo publicitario posee es operar como un mecanismo de comunicación ${ }^{14}$, como proceso de transmisión de informaciones de un emisor a un receptor por medio de un canal. Esta actividad

13 Para la caracterización de los «ejes isotópicos-semánticos» véase Greimás, Semántica estructural, Madrid, Gredos, 1973.

14 Cfr. D. A. Aaker y Myers; Management..., cit., T.I, pp: 173. 
requiere la existencia de factores individuales y sociales que suponen una transformación sobre el entorno que los envuelve. La actividad comunicativa se realiza para conseguir un determinado fin, para transformar, de algún modo, el comportamiento último del receptor.

Dicha actividad se articula, según Bernárdez, en «motivación, finalidad y realización ${ }^{15}$. La importancia de esta estructuración interna de la actividad se debe, sobre todo, a la existencia de estas operaciones como componentes de la acción global o macro-acción ${ }^{16}$.

Este macro-acto de habla en el que se fundamenta toda comunicación verbal es específico de cada tipo discursivo $\mathrm{y}$ «depende de varios factores cognoscitivos importantes que incluyen los conocimientos, las creencias, los deseos, los intereses, los objetivos, las actitudes, las normas y los valores de los usuarios de la lengua» ${ }^{17}$.

Pero no olvidemos que estos factores están, a su vez, influenciados por la comprensión del discurso; por ello, debe ser investigado cómo se formulan y se transforman por medio de los mensajes verbales que ahora tratamos.

La publicidad e: un medio de comunicación masiva que intenta dar a conocer algo, impartir información, desarrollar actitudes o inducir acciones, bien inmediatas o bien a largo plazo. Se espera, finalmente, que esta función de comunicación cree una respuesta de comportamiento en el consumidor y, en general, en el mercado.

Este mercado puede resultar en una primera compra de la marca, en el acto de continuar comprando la marca o, simplemente, en una visita al punto de venta. Esta última respuesta del comportamiento aparece mi yoritariamente en la publicidad que llevan a cabo los concesionarios automovilísticos; a este respecto, es habitual encontrar enunciados como «tu concesionario $X$ te invita a...», "venga a su concesionario...», «compruébalo en tu concesionario X...», o bien, el que mostramos a continuación:

(t.2) «VEN A VIVIRLO A TU AIRE.

Acércate a tu concesionario Renault...

Descubre la nueva serie...

Para que puedas elegir versiones...

Ven a tu concesionario Renault más próximo

y te informaremos de las ofertas...

Acércate y vivelo».

15 E. Bernárdez, Introducción a la lingüística del texto, Madrid, Espasa-Calpe, 1982, pp: 64.

16 Para una presentación general de la denominada «Teoría de la acción» y un análisis detallado del concepto «macroacción», veánse los estudios realizados por Teun A. Van Dijk, La ciencia del texto, cit., y, sobre todo, el ya cit., Texto y contexto del mismo autor.

17 Teun A. Van Dijk, Estructuras y funciones del discurso, Madrid, Siglo XXI, 1986, pp: 98. 
El proceso de cambio de actitud y de opinión debe analizarse a la luz de sus condiciones y funciones socioculturales $\mathrm{y}$, además, tales procesos y sus contextos sociales deben ser descritos rigurosamente desde el punto de vista cognoscitivo. Por ello, sostenemos que «la influencia de los hablantes, sus discursos y sus actos se habla sobre los diversos sistemas cognoscitivos de los oyentes, así como sobre las subsiguientes acciones de éstos, no es nunca directa sino siempre sumamente indirecta» ${ }^{18}$.

Estas palabras de Teun A. Van Dijk nos son de gran utilidad para la descripción del concepto «Persuasión», en términos de actitud, con respecto a los segmentos específicos de consumidores o al mercado en general. Los objetivos publicitarios pueden ser también descritos en tales términos y, así, consistirán en tratar de cambiar una posición negativa o neutral a una positiva, o bien sustentarse y mantener una actitud positiva evitando su deterioro.

En conclusión, la mayoría de los objetivos publicitarios tratan de persuadir, mediante un amplio proceso, a los consumidores para que cambien de actitud o, en última instancia, efectúen una acción: la compra o la visita al punto de venta.

Habiendo presentado ya la función última de los objetivos publicitarios: el cambio de actitud, no podemos dejar de referirnos con mayor detenimiento al mencionado proceso de persuasión, primordial no sólo en lo referente a la fijación de los objetivos publicitarios sino al proceso específico del tipo discursivo comunicativo que ahora tratamos. Ello habrá de conducir al tratamiento específico y de estructuración tipológico-discursiva de los anuncios publicitarios. Por ello, y por su intrincada ligazón con los objetivos, el tratamiento del proceso de persuasión en el mensaje publicitario dentro del ámbito retórico de la inventio resulta del mayor interés.

Es evidente que el uso de la lengua no es sólo un acto específico, sino una parte integral de la interacción social y, más aún, si tenemos presente la lengua publicitaria en la que se acentúa su papel. El mensaje publicitario contiene algo más que meramente la información que un receptor a un emisor comunica. Ya señalamos, con anterioridad, en relación con los objetivos publicitarios, los propósitos que la comunicación publicitaria desea llevar a cabo.

Si entendemos el propósito como «un estado de mente en el que tengo una representación de un estado de cosas o sucesos futuros necesitados junto con la indicación de que este fin debe ser ocasionado por una acción (de símismo) ${ }^{19}$ comprenderemos que el propósito publicitario es el inicio de una intención particular de acción o bien de un plan de acción, propuesto y deseado por el emisor-agente, para que se ejecute en una situación específica, en un tiempo y

18 Cfr. T. A. Van Dijk, Estructuras..., cit., pp: 100.

19 T. A. Van Dijk, Texto y contexto, cit., pp: 258. 
lugar concretos. Por consiguiente, el agente publicitario desea llevar a cabo un plan de acción que se traducirá en el propósito o en la intención del cambio de actitud por parte del receptor.

Esto nos hace pensar que el plan de acción es claramente, en términos publicitarios, un «Plan de Persuasión» ${ }^{20}$, que implica un cambio de estado en el comportamiento del receptor.

En síntesis, el deseo de motivación con un propósito o intención concreta, por parte del emisor, se lleva a término mediante un proceso de persuasión que se expresa por medio del mensaje publicitario. Sería éste el primer estadio en el plan persuasivo; a saber, «la atención». El mensaje es recibido, «interpretado», por el receptor, satisfactoriamente, cuando en éste se produce un cambio, entendido como estado final, distinto del presentado micialmente.

Una vez delimitada claramente la intención o el propósito inicial del emisor, del cambio de actitud o comportamiento final del receptor, debemos prestar atención al proceso que la publicidad y el mensaje publicitario siguen para que tal final se produzca.

La noción de proc`so, que presentamos a continuación, debe ser interpretada en términos publicitarios; esto es, como un proceso de persuasión: «consideramos a los procesos como sucesos continuos que ocurren durante un período de tiempo, del que no pueden distinguirse, o no se distinguen convencionalmente, los sucesos intermedios (...). En la percepción y descripción del suceso el foco de atención está en las propiedades del cambio mismo más que en la diferencia entre el estado inicial y el final ${ }^{21}$.

Estos sucesos continuos intermedios, que se hallan englobados en dos estadios primordiales (la atención y la interpretación) son los que fundamentan y dan existencia propia al proceso de persuasión publicitaria. El estado final que se persigue en el plan publicitario es la acción concreta de la compra pero, basándonos en la propuesta de Teun A. Van Dijk, el estado final de la compra no posee «el foco de atención» sino que es el cambio de actitud, de opinión o de comportamiento el punto de mira que la publicidad persigue. Estos serían los sucesos continuos de los que Van Dijk nos habla y que entrarían a formar parte del proceso de persuasión que esquematizamos a continuación:

20 Entendemos el «plan de persuasión» como un subtipo del «plan de acción», prototípico en este tipo discursivo.

${ }^{21}$ T. A. Van Dijk, Texto y contexto, cit., pp: 245. 
(3)

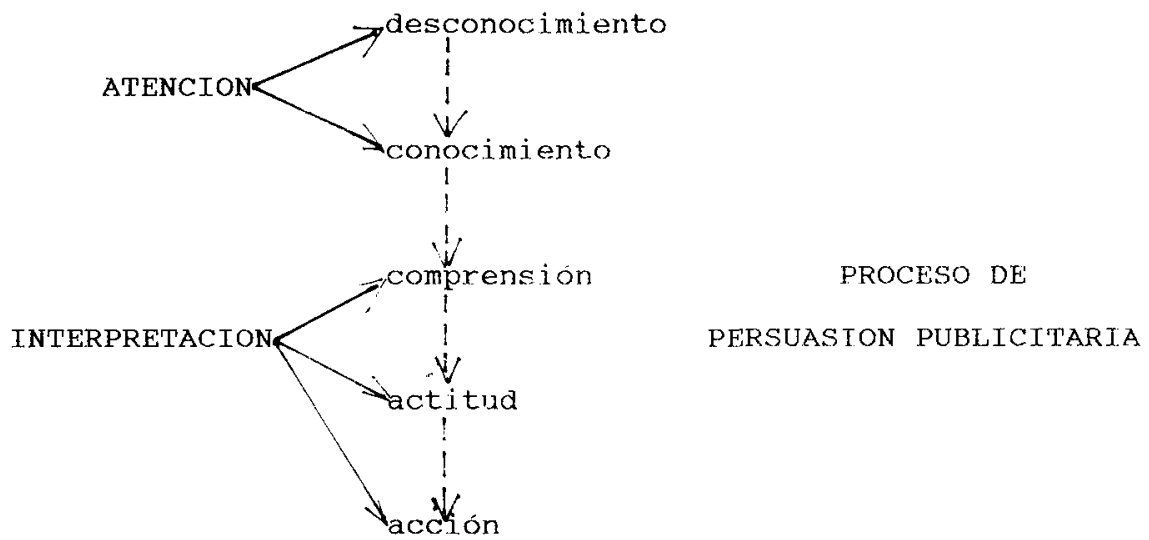

Este proceso de persuasión, denominado por Aaker y Myers «matriz de persuasión $\aleph^{22}$ combina por un lado, la visión particular de la Jerarquía de componentes de la comunicación (fuente, mensaje y canal); por el otro, la Jerarquía de respuesta, esto es, los objetivos del comportamiento, entendidos éstos como diferentes tipos de variables independientes las cuales, además de ser cuantificables, constituyen cada uno de los pasos por los que atraviesa el receptor durante el proceso de persuasión ${ }^{23}$. En conclusión, el esquema presentado en (3) quedaría completado del siguiente modo:

(4)

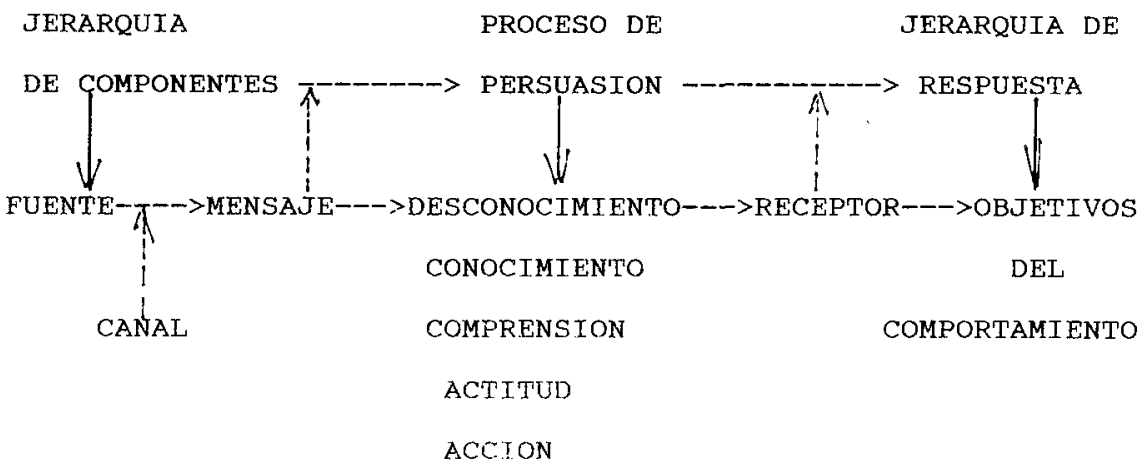

22 Cfr. Aaker y Myers, op., cit., T. II, pp: 68.

23 Para un estudio detallado de estas variables independientes y su funcionalidad dentro del marco de la matriz persuasiva, véase Aaker y Myers, op. cit., T. II, pp: 69 y ss. 
Podemos sostener que «un oyente debe tener una representación cognoscitiva, parcial, del tipo de contexto, del marco social utilizado, la categoría de los participantes, las diversas reglas o convenciones del contexto y del marco, finalmente, el momentáneo estado de interacción con el hablante $\gg^{24}$.

Todos estos elementos, que hemos presentado esquemáticamente en (4), influyen decisivamente en el proceso de persuasión publicitaria a la que el receptor se halla abocado. Estos componentes, que entran a formar parte de la jerarquía comunicativa publicitaria, y que son decisivos en la jerarquía de respuesta, poseen, inicialmente, una clara función expresada en el primer estadio del proceso persuasivo, a saber «la atención». Todo lo que la fuente expresa mediante el mensaje, ubicado en el medio publicitario, persigue primordialmente introducirse en la mente del receptor para poder llegar a los efectos anteriormente mencionados. Veamos a continuación de qué modo estos componentes manifiestan sus estímulos para llamar la atención al receptor que deberá interpretarlos tal y como éstos desean que se interpreten.

\section{II.- LA DISPOSITIO DEL MENSAJE PUBLICITARIO}

Evidentemente, y como Aristóteles expresa a lo largo de su Ars poética, sin la palabra y su estructura el pensamiento no es preciso, no es claro ni equilibrado. Por consiguiente, el publicista, habiendo hallado el propósito y la intención que le llevan a comunicarse, debe expresar tal intención a través de las palabras, que crearán las estructuras persuasivas en la mente del receptor al que llevarán al reconocimiento y a la interpretación satisfactoria de lo expresado por dicho emisor.

Si las mismas palabras y su utilización publicitaria poseen claramente elementos denotadores persuasivos, más aún los poseen las estructuras que ellas conllevan, estructuras que no han sido tomadas al azar sino meditadas desde el comienzo de la implantación de los objetivos publicitarios.

Globalmente, el mensaje publicitario se refiere tanto al contenido del mimo como a la ejecución del anuncio; es decir, es la totalidad del «input ${ }^{25}$ que recibe el receptor. Por consiguiente, en el mismo anuncio se establece una serie de relaciones que son propias de toda estructura comunicativa con la salvedad de saber que con el anuncio nos encontramos ante un estímulo claro que inicia una gama de mecanismos y estímulos-respuestas en el comportamiento último del receptor.

\footnotetext{
24 Cfr. T. A. Van Dijk, Estructuras..., cit, pp: 96.

25 Cfr. A. Aaker y Myers, Management..., cit., T.II, pp; 8.
} 
A este respecto, es de gran interés analizar el esquema que Aaker y Myers nos muestran acerca de las relaciones que se establecen en el mensaje publicitario ${ }^{26}$ :

(5)

$$
(+/-)
$$

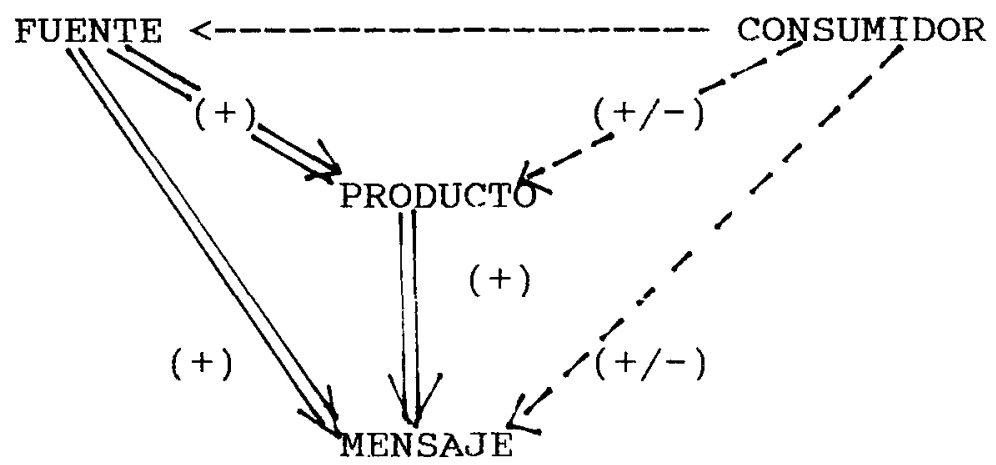

Este modelo esquemático presenta los conceptos básicos que, en lo que se ha denominado «Teoría del equilibrio» ${ }^{27}$, se establece en el anuncio publicitario.

Las relaciones $(+)$, también llamadas «equilibradas», son esencialmente estables y no originan ninguna fuerza que provoque cambios cognitivos o afectivos de comportamiento. Las relaciones fuente-producto/fuente-mensaje/ mensaje-producto han sido establecidas positivaménte y son ellas mismas las que ejercen gran fuerza para conseguir del receptor una actitud también positiva y no negativa, actitud ésta última muy posible; por ello, las relaciones consumidorfuente/consumidor-producto/consumidor-mensaje quedan sometidas a la evaluación del mismo consumidor sobre un comportamiento en particular.

De igual modo, las líneas dobles caracterizan las relaciones denominadas de «unidad». Relaciones que se refieren al grado por el cual los elementos son asociados como un todo durante el proceso de percepción del receptor.

El mensaje publicitario es un mensaje persuasivo con una estructura análoga o analógica a aquellos tipos de mensajes estudiados en psicología social; así, nos encontramos con tres claros elementos propios de tales mensajes. Estos son: la fuente $(\mathrm{F})$, la necesidad $(\mathrm{N})$ y el objeto $(\mathrm{O})$. Las relaciones que establecen dichos elementos vienen representadas en el siguiente esquema:

\footnotetext{
26 A. Aaker y Myers, op. cit., T.II, pp: 126.
}

27 Esta teoría está relacionada con la tensión que origina en el individuo el aprendizaje y la comprensión de los textos, y, sobre todo, el cambio de actitud. Dicha teoría está asociada con las relaciones entre los elementos de la comunicación y con el pronóstico de los efectos de dichas relaciones sobre el cambio de actitud. Para mayor precisión véase Aaker y Myers, op. cit., T.II, pp: 121 y ss. 
(6)

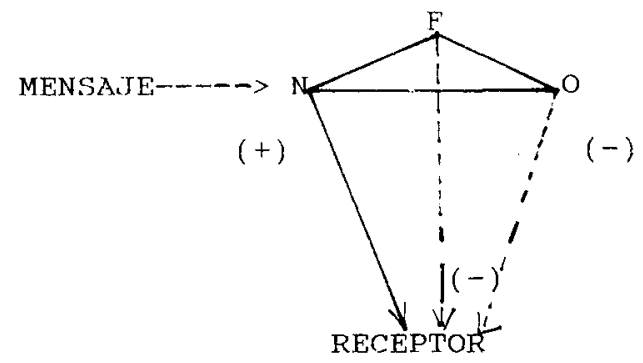

El anuncio utiliza algún tipo de fuente que sirve de conexión entre la necesidad del receptor que ha de ser satisfecha y el objeto ofrecido para satisfacerla. Tanto la fuente como la necesidad o el objeto poseen también relaciones ya establecidas, relaciones consideradas positivas. Además de esto, es evidente que la relación entre la necesidad y el receptor es positiva, ya que es el mismo receptor el que se acerca al mensaje para lograr satisfacer una necesidad propia. Esta relación positiva receptor-necesidad no conlleva un igual equilibrio con la relación que él posee para con el objeto o la fuente: es posible que el receptor tras haberse acercado al mensaje buscando la satisfacción de su necesidad no logre encontrarla por varios motivos, entre ellos, la no aceptación del producto y sus características o bien la disonancia con lo que la fuente le comunica. Por consiguiente, las relaciones que presentamos con línea discontinua son relaciones no establecidas por el receptor positivamente; será el mensaje persuasivo el que haga que estas relaciones sean aceptadas o no por el receptor satisfactoriamente.

Como ejemplo de lo que venimos expresando tomamos un prototípico anuncio publicitario:

(t.3) «La sorpresa de la potencia

Peugeot 106

La revolución del espacio».

Las relaciones que podemos establecer en el presente anuncio son las siguientes:

(7)

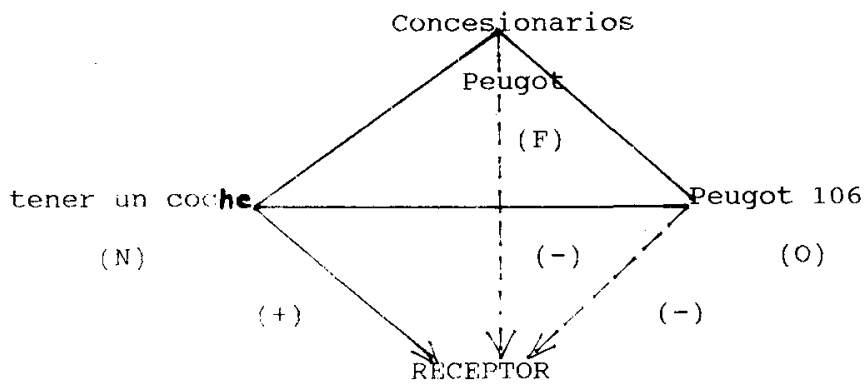


Si partimos de una clara premisa, esto es, la necesidad del receptor de comprar un coche, podemos suponer que su atención se centrará en todo aquel anuncio relacionado con la publicidad que llevan a cabo los concesionarios automovilísticos; si esta necesidad se centra más aún en este tipo de vehículos, claramente la atención del receptor tomará interés en este texto; pero aun así, será el mismo texto persuasivo el que ayude finalmente a la elección del receptor del mencionado vehículo. Para esto, el mensaje publicitario deberá ser absolutamente persuasivo: el concesionario mostrará todas las ventajas que, con la compra, el receptor tendrá si su elección está en el Peugeot 106. Para ello se especificarán persuasivamente las características del producto que ya en el encabezamiento se expresan, esto es, la potencia o el espacio del mismo.

Es en esta función específica del anuncio; es decir, el establecimiento de relaciones positivas y satisfactorias entre el receptor-fuente y receptor-objeto, donde entra en juego la estructura propia del texto persuasivo.

Inicial y globalmente todo anuncio posee tres partes claras y bien definidas en la estructura general del manifiesto publicitario, que pasamos a analizar:

i.- EL ENCABEZAMIENTO: el título o «headline», como también se le ha denominado, posee la misión primordial de establecer el primer contacto con el receptor. Se inicia la llamada «persuasión inmediata» por su mayor capacidad para atraer la atención del destinatario. El encabezamiento cumple un doble cometido: «conquistar al lector, planteando una propuesta de su interés e impulsarle a leer el resto del anuncio ${ }^{28}$. Por consiguiente, el papel principal del encabezamiento será la presentación de una información concisa, como corresponde a todo título.

ii.- EL CUERPO DE TEXTO: ésta es una de las partes que puede omitirse libremente a juicio del emisor. Si existe, el cuerpo de texto está dedicado al tema, dando una explicación o desarrollando lo ya expresado en el encabezamiento. Mayoritariamente el cuerpo de texto suele dividirse en «proposición» y «razonamiento»"29.

ii.i.- La proposición está dedicada a una simple función comunicativa y mostrativa del producto.

ii.ii.- El razonamiento, que sigue a la proposición, tiene como función acreditar lo presentado anteriormente por ésta. Es en este momento cuando se exponen los argumentos más variados; desde aquellas razones objetivas que tratan de persuadir intelectualmente al lector, a las razones subjetivas, que persiguen la persuasión afectiva.

28 Cfr. E. Feliú García, op. cit., pp: 281.

29 Para mayor precisión de ambos conceptos véase Cardona-Berasarte, Lingǘstica de la publicidad, Barcelona, Júcar, 1979, pp: 99 y ss. 
iii.- LA RÚBRICA: posee también como función primordial el establecer contacto inmediato con el receptor. Esta conclusión señala como cierto todo lo anteriormente dicho, e incluso, en la mayoria de las ocasiones, lo reitera, dándole un nuevo impacto sugestivo al nombre de la marca.

En consecuencia, un anuncio quedaría estructurado del siguiente modo ${ }^{30}$;

$$
\begin{aligned}
& \text { Encabez. } {\left[\begin{array}{l}
\text { "YA HAY } 56.000 \\
\text { OFICINAS DE FÉNIX AUTOS } \\
\text { EN MURCIA }
\end{array}\right.} \\
& \text { prop. } \quad\left[\begin{array}{l}
\text { Porque en Murcia hay } 56.000 \text { teléfonos, y donde } \\
\text { haya un teléfono, ahí está Fénix Autos. Porque } \\
\text { los seguros Fénix Autos se pueden contratar } \\
\text { directamente por teléfono o en nuestra nueva } \\
\text { oficina de Plaza Santa Catalina, } 1 .
\end{array}\right.
\end{aligned}
$$

razn.

con toda rapidez y comodidad. Con un servicio ágil y moderno. Eficaz al primer contacto. Por eso tu teléfono es una de nuestra oficinas.

Infórmate 900-111-222

Rúbrica

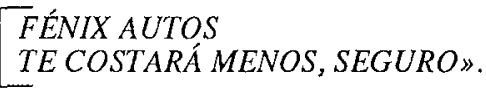

El encabezamiento señala el inicial punto de mira gracias al contenido que expresa. Cualquier lector reparará en este texto ante la afirmación establecida, esto es, la existencia de 56.000 oficinas en Murcia.

Esa rotunda y persuasiva afirmación es explicada en el cuerpo de texto. En el primer parágrafo, la proposición vuelve a presentar la increíble cifra, pero es ahora donde se clarifica y se muestra la realidad de tal cifra: no son oficinas sino teléfonos. La proposición comunica simplemente la cualidad del producto, en este caso, servicio: la posibilidad de contratar seguros por teléfono.

El segundo parágrafo, equivalente a lo que hemos denominado razonamiento, acredita lo expuesto en el anterior. Los argumentos que se dan acerca de la calidad del servicio son altamente subjetivos; se menciona la rapidez, la comodidad, la agilidad, la modernidad y la eficacia, valores éstos muy apreciados por cualquier receptor. El emisor persigue con esto la persuasión afectiva y más aún si tenemos en cuenta la importancia personificada que se le da a la existencia del teléfono, importancia en la cual el receptor se ve involucrado con la frase «por eso tú teléfono es una de nuestras oficinas» ${ }^{31}$.

30 Hemos tomado como ejemplo un tex to completo en lo referente a sus partes estructurales. La existencia de otros tipos de textos en cuanto a su estructura es sumamente variada.

31 El subrayado es nuestro. 
La rúbrica vuelve a señalar el nombre de la empresa anunciadora, nombre que ha sido repetido persuasivamente tres veces en los parágrafos anteriores. Es de destacar el enunciado último, formando éste parte central, no sólo de la rúbrica en la cual se encuentra ubicado, sino también en el icono global del anuncio, además de su destacado valor dentro de la campaña anunciadora.

$\mathrm{Si}$ analizamos el enunciado «Te costará menos, seguro» vemos en él condensado todo el texto anterior. Asi, el verbo central y único "costará»» denota no sólo el ahorro económico, refiriéndose al elevado precio habitual de los seguros; además, con este verbo se señala la comodidad de usar el teléfono para concertar seguros, lo que implica mayor comodidad y, por consiguiente, menor coste; el consumidor no tendrá necesidad de desplazarse hasta la oficina de la empresa anunciadora por la ya mencionada razón de que «tu teléfono es una de nuestras oficinas». Mayor valor connotativo posee la forma afirmativa «seguro», la cual fundamenta positivamente todo lo expresado en el texto. Dicha forma puede ser tomada también como sustantivo englobando, en él mismo, el discurso persuasivo, esto es, la propaganda de los seguros Fénix Autos.

\section{III.- LA ELOCUTIO DEL MENSAJE PUBLICITARIO}

Ya mencionamos la importancia que la elocutio encierra no sólo en lo referente a su relación con los otros componentes retóricos - inventio y dispositio-en el corpus global de la retórica, al ser ella quien suministra «el ropaje lingüístico» ${ }^{32}$ a las ideas que, halladas en la mente y dispuestas de modo estructural, son trasladadas al lenguaje. También la elocutio proporciona consistencia y valor a la gramática ya que se halla emparentada con ésta directamente. La relación que entre gramática-elocutio, esto es, gramática-retórica, se propone está fundamentada en la corrección del lenguaje bien como «ars recte dicendi» o bien «ars bene dicendi», respectivamente.

Es en esta presentación del término «elocutio» y sus relaciones, tanto con los otros componentes retóricos, como con la gramática, donde basamos nuestro análisis (I) del mensaje publicitario. Por ello, vemos necesario analizar estas relaciones que nacen, y parten, del concepto de «elocutio».

La relación inventio-elocutio se refiere al qué y al cómo de las ideas; por consiguiente, la elocutio se presenta como materialización y encarnación de aquéllas a través de los distintos códigos, ya mencionados con anterioridad. La relación dispositio-elocutio se halla determinada en el discurso por el binomio res-verba. Teniendo en cuenta que la dispositio se refiere tanto a las res como a

32 Cfr. H. Lausberg, Manual de retórica literaria, Madrid, Gredos, T.II, pp: 9. 
los verba y que la elocutio se relaciona directamente con éstos, basamos nuestro análisis del mensaje publicitario, ya no manifiesto publicitario, en su concepción como mensaje lingüístico estructural. Por ello, deberian ser también abordados problemas concernientes a la dispositio, ya que el mensaje publicitario necesita ser analizado a la luz de su estructura tripartita, no sólo por cuestiones estilísticas (son muy distintas las figuras retóricas que podemos encontrar en el encabezamiento del anuncio, como parte inicial del proceso persuasivo, a las halladas en el cuerpo del texto, como explicación y caracterización del objeto anunciado), sino también por cuestiones perceptivas: el lenguaje persuasivo utilizado en el encabezamiento como primera llamada de atención será muy distinto al presentado por la rúbrica que reiterará lo ya expuesto por aquél.

En conclusión, esta relación dispositio-elocutio vendrá caracterizada por la conjunción lingüístico-estructural.

Hablar del mensaje lingüístico en el conjunto del manifiesto publicitario supone caracterizar elocutivamente al mismo y, por ello, es importante que analicemos este mensaje desde tres niveles intrínsecos en su conjunción, a saber: el de su configuración, y con éste, el plano expresivo y el del contenido. Valoremos, pues, cada uno de ellos:

i.- La configuración global del mensaje lingüístico: Con su configuración el manifiesto publicitario retoma los elementos pertenecientes a los diversos códigos utilizados por la misma publicidad en lo que se ha denominado «el mensaje de pertenencia al género ${ }^{33}$, ya que será la configuración global del texto, lingüisticamente hablando, junto con la utilización de las marcas propias del género, las que identifiquen al tex to publicitario como tal; y ello, en virtud, precisamente, de la configuración del mensaje lingüístico, que se caracteriza por la sobresignificación, por la «aplicación de un código formal distinto ${ }^{34}$.

Uno de los fenómenos más interesantes que afectan a la configuración lingüística y que al mismo tiempo forma parte del mensaje de pertenencia al género consiste en la sustitución de algunos grafemas por elementos no grafemáticos, como ocurre en el siguiente texto:

\section{(t.5) «CERRAJERÍA DIEGO»}

En este texto la primera /e/ de «cerrajería» ha sido sustituida por una llave que identifica claramente el término lingüístico con su concepto semántico; del mismo modo la vocal /o/ de «Diego» representa una cerradura. Aquí podemos comprobar cómo estas sustituciones están generalmente fundadas en la analogía

33 Para una mayor caracterización sobre el concepto «mensaje de pertenencia al género», véase el ya cit. Los Lenguajes de la publicidad, pp: 142-147.

${ }^{34}$ Cfr. E. Feliú García, op. cit., pp: 148. 
formal entre unos y otros elementos; esto es, entre el grafema y su semejanza con la figura mostrada; en este caso una llave y su cerradura. Claramente la componente icónica, como código de sobresignificación, refuerza la forma y el contenido semántico connotativo del vocablo.

Otro de los fenómenos que podemos encontrar está caracterizado por la disposición tipográfica en combinación con elementos de distinta naturaleza. Este es el caso del texto siguiente;

(t.6) «La videocámara más ligera no es de...

ni de..., ni de...

Es de Canon»

ii.- El plano de la expresión: En cuanto a este segundo nivel propio del mensaje lingüístico es importante destacar la gran variedad de manipulaciones de las cuales pueden ser objeto. Estas manipulaciones son de tres tipos: por obliteración, por suspensión o por transgresión ${ }^{35}$, esto es; "según se dé ausencia del significante, imposibilidad de adscripción de significado a un significanteo sustitución de significante» ${ }^{36}$.

La función básica de estas tres formas concretas es el enigma, que mediante el significante se transfiere al significado y con ello al plano semántico.

Este enigma semántico, que mayoritariamente se representa en la omisión de la componente escrita, es muy utilizado en los últimos años, en los que la publiciadad se lleva a cabo mediante episodios. El receptor sabe que tiene ante sî un anuncio, pero no sabe lo que se anuncia, esperando la resolución del enigma en otro texto que se presentará días más tarde ${ }^{37}$. Lo que se pretende con este tipo de campañas episódicas es crear un cierto suspense, como lo evidencian los siguientes textos:

(t.7) «En el '92, ¿dónde encontrarán un

Inglés, una Turca, una Italiana y

un Candiense? »

días más tarde aparece,

(t.8) «En Mobiliaria '92 encontrará

desde un escritorio inglés,

hasta una cama turca, desde una sierra italiana, hasta un pino candiense, desde...”

35 Cfr. G. Péninou, Semiótica de la publicidad, Barcelona, Gustavo Gili, 1976.

36 E. Feliú García, op. cit., pp: 150.

${ }_{37}$ En numerosas ocasiones el enigma se resuelve con otro texto que aparece en el mismo periódico y en el mismo día pero en distinta página. 
Otros señalan el enigma explícitamente;

(t.9) «Pronto descubrirá un divertido juego con el que podrá ganar fantásticos premios».

días más tarde

(t.10) «Es La Verdad

Es nuestro juego de Batalla Naval

Pronto descubrirá las bases»

Con tales textos nos hallamos, consiguientemente, ante una obliteración parcial, ya que tal procedimiento llega a ser absoluto cuando incluso desaparecen los significantes escriturales y sólo se presenta el objeto anunciado o parte de éste.

El fenómeno de transgresión junto con la suspensión o sustitución de significantes es casi consustancial a la publicidad y puede adoptar las más variadas formas; una de las más extremadas es la utilización de otro código lingüístico como son los usos de las lenguas extranjeras que caracterizan no sólo este mensaje lingüístico sino también el mensaje de pertenencia al género si tenemos en cuenta el valor retórico que posee.

La sustitución de significantes no sólo puede producirse por la utilización de alguna lengua extranjera sino también por la denominada «hipercaracterización ortográfica», que consiste en «alterar la grafía de una forma para que llegue a ostentar otras características no propias» ${ }^{38}$.

En el siguiente anuncio se ha sustituido el grafema $/ c /$ por $/ k /$, sirviéndose de la identificación que ambos alófonos poseen - sin llevar, por consiguiente, a alteraciones rítmicas y sonoras - para hacer aparecer la analogía del vocablo «ekonómico» con la marca del automóvil «Aleko», funcionando de este modo de forma connotativa y poética;

(t.11) «Aleko

De los grandes,

el ekonómicos ${ }^{39}$

iii.- El plano del contenido: el tercer aspecto que debe considerarse en el mensaje lingüístico es el referente al de su contenido. Éste entraña a veces un problema de difícil solución, puesto que la información contenida en un manifiesto no se adscribe a una u otra de sus componentes (icónica y lingüística).

\footnotetext{
38 Cfr. E. Feliú García, op. cit., pp: 63.

39 Véase también el ritmo poético entre -aleko- y -el eko-
} 
De este modo, en ocasiones encontramos que la función instrumentalizadora del texto se opone a la función lúdica de la imagen; por ello, se llega, incluso, a utilizar el tex to como mero instrumento haciendo que la imagen sea el sustentador mayor del anuncio.

Por otra parte, no podemos olvidar la importante función que el lenguaje posee y que en numerosas ocasiones lo salva de ser este instrumento mediador para convertirse nuevamente en el soporte del anuncio. Nos referimos a la función poética ${ }^{40}$. En otros casos la imagen relega su papel y adquiere, por ello, una función monosemizadora y concretizadora de la plurivocidad, normalmente intencionada en publicidad, del lenguaje.

De todos modos, las relaciones entre tex to e imagen son de una complejidad harto difícil de reducir, como en ocasiones se pretende. Lo que sí resulta cierto es la dificultad de adscribir la información del manifiesto al mensaje lingüístico o al icónico, con los consiguientes problemas a la hora de considerar la materia del contenido tanto en una como en otra componente.

Este análisis de la estructura retórica del texto en sí (elocutio) nos ha llevado a sostener que las reglas que se refieren a la estructura del texto deben obedecer a una serie de criterios generales que fijan su idoneidad: la claridad y transparencia de estilo, la interacción comunicativa, la utilización «pura» de la lengua, concordando con la gramática habitual y otros usos y valores que ayudarán a la interpretación satisfactoria del texto persuasivo.

Pero, este estado de cosas ha llevado con frecuencia a suponer que «sólo el texto literario posee estas estructuras especiales, olvidándose que tienen una función comunicativa mucho más general y que pueden presentarse en los más diversos tipos de textos ${ }^{41}$. Por ello, nosotros lo hemos intentando con el TEXTO PUBLICITARIO.

40 Cfr. R. Jakobson, Lingüística y poética, Madrid, Cátedra, 1981.

41 Cfr. T.A. Van Dijk, La ciencia del texto, Barcelona, Paidós, 1983, pp: 128. 